\title{
Effect Of Aspirin on Haematological and Plasma Biochemical Parameters in Male Albino Rats
}

\author{
Oyedeji K.O. ${ }^{1}$, Bolarinwa A.F. ${ }^{2}$, Adeyemo C.O. ${ }^{3}$ \\ ${ }^{I}$ Department of Physiology, College of Medicine and Health Sciences, Afe Babalola University, Ado-Ekiti, \\ Nigeria \\ ${ }^{2}$ Department of Physiology, College of Medicine, University of Ibadan, Ibadan, Nigeria. \\ ${ }^{3}$ Department of Physiology, Ladoke Akintola University of Technology, Ogbomoso, Nigeria.
}

\begin{abstract}
The effect of oral administration of $10 \mathrm{mg} / \mathrm{kg} B W$ of aspirin on haematological and plasma biochemical parameters in albino rats were investigated. The aspirin was administered on daily basis for 30 days and blood samples were collected for analyses.

Treatment of rats for 30 days with $10 \mathrm{mg} / \mathrm{kg} \mathrm{BW}$ of aspirin caused significant $(p<0.05)$ reductions in $P C V, H b, T W B C$ and monocyte values relative to their respective controls; but caused significant $(p<0.05)$ increments in the activities of AST and ALT relative to their respective controls.

These findings probably indicates that aspirin have deleterious effect on the blood chemistry of male albino rats. Key words: Aspirin, Red blood cell, Total white blood cell, Albumin, Albino rats.
\end{abstract}

\section{Introduction}

Aspirin also known as acetylsalicytic acid, first isolated by a German Chemist called Felix Hoffmann, is a salicylate drug, often used as an analgesic to relieve minor aches and pains, as an antipyretic to reduce fever, and as an anti-inflammatory medication (Sneader 2000; Schror 2009).

Aspirin is used in the treatment of a number of conditions including fever, pain, rheumatic fever and inflammatory diseases such as rheumatoid arthritis, pericarditis and Kawasaki disease (TASHSP, 2011). Aspirin has been reported to be used in preventing heart attack and strokes (Hall and Lorenc, 2010), colorectal cancer (Manzano and Perez-Segura, 2012) as well as myocardial infarction (BNF, 2003). Aspirin has been reported to cause tinnitus based on experiments in rats (Guitton et. al., 2003) and increase the risk of gastrointestinal bleeding (Sorensen et. al., 2000).

However, due to scanty information from literature on the effect of aspirin on haematological and plasma biochemical parameters in animal models, this study therefore aims at investigating the effect of aspirin on these aforementioned parameters in male albino rats.

\section{Experimental Animals}

\section{Materials and Methods}

Adult male albino rats weighing between $160 \mathrm{~g}$ and $180 \mathrm{~g}$ bred in the Animal House of Physiology Department, LAUTECH, Ogbomoso were used. They were housed under standard laboratory conditions with a 12 hours daylight cycle and had free access to feed and water; they were acclimatized to laboratory conditions for two weeks before the commencement of the experiments. All experiments were carried out in compliance with the recommendations of Helsinki's declaration on guiding principles on care and use of animals.

\section{Drug}

Aspirin tablets (Green Field Pharm Ltd) were bought from Geopat Pharmacy, Ogbomoso, Nigeria. Two hundred and fifty milligram $(250 \mathrm{mg})$ of aspirin was dissolved in $10 \mathrm{ml}$ of distilled water to give a concentration of $25 \mathrm{mg} / \mathrm{ml}$.

The dosage of aspirin administered in this study was in accordance with that reported by Chaloob et. al., 2009.

\section{Experimental Design}

Ten animals were randomly divided into two groups with each group consisting of five rats. The two groups of rats were subjected to the following oral treatments once a day for 25 days:

Group I rats received $10 \mathrm{mg} / \mathrm{kg} \mathrm{BW}$ of aspirin.

Group II rats received $0.5 \mathrm{ml}$ of distilled water as the control group.

Twenty-four hours (day 31) after the last dosing of the four groups, blood samples were collected. 


\section{Collection of Blood Samples}

Blood samples were collected through the medial cantus into EDTA bottles for haematological and plasma biochemical studies. Before assays, the blood samples were centrifuge for 5 minutes using a bench-top centrifuge (Centromix) and the supernant plasma was then used for the determinations of the biochemical parameters.

\section{Determination of Haematological Parameters}

The red blood cells (RBC) and white blood cells (WBC) counts were determined by the improved Neubauer haemocytometer method. The haemoglobin $(\mathrm{Hb})$ concentration was determined according to Jain (1986), using the cyanomethaemoglobin method. The packed cell volume (PCV) was determined by the microhaematocrit method according to Dacie and Lewis (1991). Schilling method of differential lecukocyte count was used to determine the distribution of the various white blood cells (Mitruka and Rawnsley, 1977). Mean corpuscular volume (MCV), mean corpuscular haemoglobin $(\mathrm{MCH})$ and mean corpuscular haemoglobin concentration (MCHC) were computed according to Jain (1986).

\section{Determination of Plasma Biochemical Parameters}

The total protein concentration was determined using the Biuret method (Reinhold, 1953) and the albumin concentration by the method of Doumas et al. (1971). The globulin concentration was calculated by subtracting the albumin concentration from the total protein concentration. Activities of plasma alanine transaminase (ALT) and aspartate transaminase (AST) were determined according to the method of Duncan (1994). The level of cratinine was determined using the method of Tietz et al. (1994). All the above biochemical parameter were determined in the plasma using the Randox kits.

\section{Statistical Analysis}

The mean and standard error of mean (S.E.M.) were calculated for all values. Comparisons between the control and the treated groups were done using the student's t-test. Differences were considered statistically significant at $\mathrm{p}<0.05$.

\section{Results}

The effect of $10 \mathrm{mg} / \mathrm{kg} \mathrm{BW}$ of aspirin on haematological and plasma biochemical parameters of albino rats after treatment of rats for 30 days are shown respectively in Tables 1 and 2.

Treatment of rats with $10 \mathrm{mg} / \mathrm{kg} \mathrm{BW}$ of aspirin caused significant $(\mathrm{p}<0.05)$ reductions in $\mathrm{PCV}, \mathrm{Hb}$, TWBC and monocyte values relative to their respective controls; but caused insignificant ( $p>0.05)$ changes in RBC, platelet, lymphocyte, neutrophil, eosinophil and the hematmetric indices (MCV, MCHC, MCH) values relative to their respective controls.

Treatment of rats with $10 \mathrm{mg} / \mathrm{kg} \mathrm{BW}$ of aspirin caused significant $(\mathrm{p}<0.05)$ increase in the activities of AST and ALT relative to their controls, but caused non-significant ( $p>0.05$ ) changes in total protein, albumin, globulin and creatinine levels relative to their respective controls.

Table 1: Effect of $10 \mathrm{mg} / \mathrm{kg} \mathrm{BW}$ of Aspirin on the Haematological parameters of rats ( $\left.\mathrm{n}=5,{ }^{*} \mathbf{p}<0.05\right)$

\begin{tabular}{lll}
\hline Parameters & Control & $\mathbf{1 0 ~ m g / k g ~ A s p i r i n ~}$ \\
\hline PCV\% & $50.20 \pm 1.88$ & $43.60 \pm 0.98^{*}$ \\
$\mathrm{HB}(\mathrm{g} / \mathrm{dl})$ & $15.54 \pm 0.50$ & $13.68 \pm 0.35^{*}$ \\
$\mathrm{RBC}(\mu \mathrm{L})$ & $6.52 \pm 0.70$ & $7.91 \pm 0.32$ \\
MCV $(\mathrm{F} / \mathrm{l})$ & $57.20 \pm 1.44$ & $55.20 \pm 1.22$ \\
MCHC $(\mathrm{g} / \mathrm{dl})$ & $19.40 \pm 1.64$ & $18.81 \pm 1.40$ \\
MCH $(\mathrm{pg})$ & $33.22 \pm 1.02$ & $32.41 \pm 1.10$ \\
TWBC $\left(\mathrm{x} 10^{3} \mu \mathrm{L}\right)$ & $9.58 \pm 7.69$ & $5.10 \pm 1.38^{*}$ \\
Platelet $\left(\mathrm{x} 10^{5} / \mu \mathrm{L}\right)$ & $1.05 \pm 0.13$ & $1.15 \pm 0.94$ \\
Lymphocyte $(\%)$ & $65.2 \pm 5.57$ & $66.6 \pm 2.50$ \\
Neutrophil $(\%)$ & $31.2 \pm 5.41$ & $32.0 \pm 2.88$ \\
Monocyte $(\%)$ & $2.00 \pm 0.32$ & $0.80 \pm 0.30^{*}$ \\
Eosinophil $(\%)$ & $28.4 \pm 5.10$ & $30.0 \pm 2.14$ \\
\hline
\end{tabular}


Table 2: Effects of 10mg/kg/BW dose of Aspirin on Plasma Biochemical parameters for 30 days $\left(\mathrm{n}=5^{*}\right.$ $(\mathbf{p}<0.05)$ significant

\begin{tabular}{lll}
\hline Parameters & Control & $\mathbf{1 0 ~ m g / k g ~ A s p i r i n ~}$ \\
\hline Total protein $(\mathrm{gm} \%)$ & $5.38 \pm 0.41$ & $5.12 \pm 0.18$ \\
Albumin $(\mathrm{gm} \%)$ & $2.28 \pm 0.22$ & $2.06 \pm 0.22$ \\
Globulin $(\mathrm{gm} \%)$ & $2.86 \pm 0.12$ & $3.32 \pm 0.36$ \\
AST $(\mu / \mathrm{L})$ & $15.33 \pm 0.88$ & $24.67 \pm 1.20^{*}$ \\
ALT $(\mu / \mathrm{L})$ & $12.80 \pm 1.20$ & $18.1 \pm 1.93 *$ \\
Creatinine $(\mathrm{mg} / \mathrm{dL})$ & $0.80 \pm 0.14$ & $0.74 \pm 0.12$
\end{tabular}

\section{Discussion}

The values obtained for RBC showed the non-significant effect of 30-day treatment of rats with aspirin on red blood cells (RBC) counts when compared with the control. This is an indication that there was no destruction of red blood cells and no change in the rate of production of RBC (erythropoiesis). This also shows that aspirin does not have the potential to stimulate erythropoietin release from the kidneys, which is the humoral regulator of RBC production (Polenakovic and Sikole, 1996). It has been reported that values of RBC and associated parameters lower than normal ranges are indicative of anemic conditions while higher values are suggestive of polycythemia (American Diabetes Association, 2000), thus, treatment of rats with aspirin may not have the potential to induce anemia or polycythemia. Also, treatment of rats with aspirin may not have adverse effects on the bone marrow, kidney and haemoglobin metabolism, since it has been reported that only substances which significantly affect the values of red blood cells and associated parameters would have effects on the bone marrow, kidney and haemoglobin metabolism (Young and Maciejewski, 1997).

Aspirin caused non - significant changes in the MCV and $\mathrm{MCH}$ values which could be an indication of absence of macrocytic anaemia since increased $\mathrm{MCV}$ an $\mathrm{MCH}$ values are known to be indicative of macrocytic anaemia. Also, aspirin caused non- significant change in the $\mathrm{MCHC}$ value which suggest and absence of hereditary spherocytosis since MCHC values are known to be elevated in hereditary spherocytosis.

The significant reductions in PCV and $\mathrm{Hb}$ values caused by aspirin could indicate induction of anaemia and decrease in oxygen- carrying capacity of the blood as well as the amount of oxygen delivered to the tissues respectively.

The significant reduction in TWBC count caused by aspirin suggests that the immune system has been compromised. Contrary report was given by Adewusi and Afolayan (2009) in Pelargonium reniforme extract treated rats.

The insignificant change in neutrophil count caused by aspirin probably indicates that the ability of the body to attack and destroy invading bacteria, viruses and other injurious agents (Phagocytosis) has not been compromised. The non-significant change in lymphocyte count suggests that the acquired immune response of the body has not been compromised by aspirin; while the significant reduction in monocyte count probably indicates that the phagocytic function of the body has been compromised by aspirin. The non - significant change in eosinophil count probably indicates that the anti-allergic and anti-parasitic infectious responses of the body have not been compromised by aspirin.Also, the insignificant change in the platelet count caused by aspirin could be an indication that it does not has the potential to stimulate thrombopoietin production (Li et al., 1999) with the hemostatic capability of the blood maintaining the status quo since platelets mediate in the blood -clotting mechanism.

Aspirin caused non-significant change in total protein levels, which probably indicates that the buffering capacity of the blood and body fluid balance have not been compromised. Contrary report was given by Adewusi and Afolayan (2009) in Pelargonium reniforme extract treated rats. Aspirin caused insignificant increase in albumin level which suggests that the plasma level of metals, ions, fatty acids, amino acids, bilirubin and enzymes have not been compromised by aspirin. Contrary report was given by Adedapo et. al., (2007) in rats treated with $P$. amarus and $C$. anontifolius extracts. Aspirin caused significant increase in the activity of ALT which probably indicates the hepato-toxic potential of aspirin. Aspirin also caused significant increase in the activity of AST which probably indicates tissue necrosis induction by aspirin. Aspirin caused insignificant change in creatinine level which suggests that the structural integrity and functions of the nephrons have not been compromised.

In conclusion, this study has shown that aspirin could have deleterious effect on the blood chemistry of albino rats, considering these findings in animal model, it is recommended that caution should be exercised in the use of aspirin. 


\section{References}

[1] American Diabetes Association (2000): Nutrition recommendation and principles for people with diabetes mellitus clinical practice recommendations Diabetes care 23:543-6.

[2] British National Formulary (BNF) (2003): British Medical Journal and Royal Pharmaceutical Society of Great Britain, 45 ed.

[3] Chaloob AK, Qasim HM, Gassim MH (2009): The effects of aspirin and fenugreek seed on the testes of white mice. Fac Med Baghdad. Vol 52, No 3: pp 349-351.

[4] Dacie JV, Lewis SM (1991): Practical haematology, 7th edition ELBS with Churchill Livingston, England, pp 37-85.

[5] Doumas BT, Watson W, Biggs HC (1971): Albumin standards and the measurement of serum albumin with bromocresol green. Clinica Chimica Acta 31, 87-96.

[6] Duncan JR, Praise KW, Mahaffey EA (1994): Veterinary Laboratory Medicine (Clinical Pathology) 3rd ed. Iowa State University Press, U.S.A.

[7] Guitton MJ, Caston J, Ruel J et. al., (2003): Salicylate induces tinnitus through activation of cochlear NMDA receptors J. Neurosci 23 (9): 3944-52.

[8] Hall SL, Lorenc T (2010): Secondary prevention of coronary artery disease. American family physician 81 (3): $289-96$.

[9] Jain NC (1986): Schalm's Veterinary Haematology 4th ed. Lea and Fabiger, Philadelphia.

[10] Li Y, Xia, Kuter DJ (1999): Interaction of thrombopoietin with the platelet complements receptor in plasma: binding, internalization, stability and pharmacokinetics. Brit J. Haematol 106: 345.

[11] Li Y, Xia, Kuter DJ (1999): Interaction of thrombopoietin with the platelet complements receptor in plasma: binding, internalization, stability and pharmacokinetics. Brit J. Haematol 106: 345.

[12] Manzano A, Perez-Segura P (2012): Colorectal cancer chemoprevention is this the future of colorectal cancer prevention? The Scientific World Journal 327341. PMID 22649288.

[13] Mitruka BM, Rawnsley H (1977): Clinical, biochemical and haematological references values in normal experimental animals. Masson Publishing USA Inc. Pp. 53-54.

[14] Polenakovic M, Sikole A (1996): Is erythropoietin a survival factor for red blood cells? J. Am. Soc Nephrol 7(8): 1178-1182.

[15] Reinhold JG (1953): Manual determination of serum total protein, albumin and globulin fractions by the Biuret method Standard Methods of Clinical Chemistry (Academic Press, New York).

[16] Schror K (2009): Acetysalicylic acid. ISBN 978-3-527-32109-4.

[17] Sneader W (2000): "The discovery of aspirin: A reappraisal". BMJ (Clinical Research ed.) 321 (7276): $1591-1594$.

[18] Sorensen HT, Mellemkjaer L, Blot WJ et. al., (2000): Risk of upper gastrointestinal bleeding associated with use of low-dose aspirin. Am. J. Gastroenterol 95 (9): 2218-24.

[19] The American Society of Health-System Pharmacist (TASHSP) (2011): “Aspirin”. Retrieved 3 April 2011.

[20] Tietz NW, Prude EL, Sirgard - Anderson O (1994): Textbook of clinical chemistry. Ed. Burtis C.A. and Ashwood E.R. pp 1354 1374. W.B. Saunders Company, London.

[21] Young NS, Maciejewski J (1997): The path physiology of acquired aplastic anemia. New Eng. J. Med., 336:1365. 